\title{
Is It Necessary to Prepare the Enamel before Dental Bleaching?
}

\author{
Andréa Dias Neves Lago, ${ }^{1}$ Patrícia Moreira de Freitas, ${ }^{2,3}$ Erika Michele dos Santos Araújo, ${ }^{1}$ \\ Adriana Bona Matos, ${ }^{3}$ and Narciso Garone-Netto ${ }^{3}$ \\ ${ }^{1}$ Department of Dentistry I, Federal University of Maranhão (UFMA), São Luís, MA, Brazil \\ ${ }^{2}$ Special Laboratory of Lasers in Dentistry (LELO), Department of Operative Dentistry, School of Dentistry, \\ University of São Paulo (USP), São Paulo, SP, Brazil \\ ${ }^{3}$ Department of Operative Dentistry, School of Dentistry, University of São Paulo (USP), São Paulo, SP, Brazil
}

Correspondence should be addressed to Andréa Dias Neves Lago; adnlago@gmail.com

Received 26 September 2016; Revised 13 December 2016; Accepted 15 January 2017; Published 9 February 2017

Academic Editor: Carlos A. Munoz-Viveros

Copyright (c) 2017 Andréa Dias Neves Lago et al. This is an open access article distributed under the Creative Commons Attribution License, which permits unrestricted use, distribution, and reproduction in any medium, provided the original work is properly cited.

The aim of this in vitro study was to assess the influence of distinct surface treatments on the microhardness and color of enamel that will be bleached. Surface treatments are tested, accordingly: G1, no treatment; G2, 2\% sodium fluoride; G3, casein phosphopeptide paste; G4, 2\% fluoride+Nd:YAG laser. Forty blocks from bovine teeth composed the sample that were tested in Knoop microhardness $(n=10)$ and in color change $(n=10)$. After $24 \mathrm{~h}$, bleaching with $35 \%$ hydrogen peroxide was performed for $45 \mathrm{~min}$. Microhardness and color changes (using parameters $\Delta E, \Delta L, \Delta a$, and $\Delta b$ ) were assessed before and after bleaching. The data were analyzed by two-way ANOVA and Tukey's test $(p<0.05)$. Despite all surface treatments, a reduction of enamel microhardness occurred immediately after bleaching in all groups, being greater in G1. Enamel color changed in all groups. Immediately after bleaching, there was a decrease on enamel microhardness. However, after 7 days, some of those specimens previously treated before bleaching significantly recovered their initial microhardness without influencing the esthetic results of bleaching.

\section{Introduction}

Effects of bleaching agents on the enamel surface have been a clinical concern as they can lead to dentinal sensitivity [1], enamel demineralization [2,3], and surface morphological changes [3-6].

Even tough professionals explain side effects of bleaching, patients still claim for this procedure. Thus, strategies which could decrease the occurrence of some of these side effects need to be further explored. Some strategies have been proposed to prevent changes in the enamel surface, such as topical fluoride application [6-8], phosphoprotein casein and calcium phosphate (CPP-ACP) [9-12], and, more recently, the use of high power lasers, such as the Nd:YAG laser [12-16]. But a question remains to be answered: will these strategies affect the effectiveness of the bleaching procedure itself?

Although the mechanism of action of fluoride in preventing caries is well known in the literature, its effect on preventing demineralization caused by bleaching agents is still controversial [6]. Fluoride, with its high affinity for calcium phosphate, contributes to the formation of complexes that precipitate on the tooth, preventing demineralization. Either way, high concentrations of fluoride in the form of varnishes and gels have shown to be effective in preventing enamel demineralization $[17,18]$.

Fluoride in saliva is also important. Some products have been developed to provide calcium [19-21] and phosphate, in addition to fluoride, to favor the remineralization process [20-22]. In this context, the use of casein, the predominant protein in milk serum, has been indicated to increase the availability of calcium, phosphate, and fluoride in the oral environment. The main function of phosphopeptides (CPP) from enzymatic breakdown of the casein molecules is to aggregate and stabilize ACP, amorphous calcium phosphate [20]. In addition to storing the ions that participate in the remineralization process, these molecules can adhere to the salivary film, biofilm, and oral tissues, so that the CPP-ACP complexes remain in the oral environment for a longer period [9]. When there is drop in $\mathrm{pH}$, these ions are slowly and gradually solubilized and will contribute to the mechanism of remineralization $[20,23,24]$. 
New technologies have been described to reduce the process of demineralization when enamel is subjected to acid challenges. Since Sognnaes and Stern (1965) [25] reported that laser light increases enamel resistance to acids, many studies have been conducted to determine conditions and parameters that effectively prevent enamel demineralization $[26,27]$, especially with laser emission in the near-infrared range with a wavelength of $1064 \mathrm{~nm}[13,15,16,27]$. Recently, a clinical study reported positive results with the use of $\mathrm{Nd}$ :YAG laser associated with fluoride in the prevention of mineral loss from enamel [15].

Given the importance of finding new methods to prevent enamel demineralization from constant acid attacks, it is important to provide patients with safer and more conservative preventive/restorative procedures that have higher clinical durability. However, it is still not known whether these prevention alternatives affect the outcome of bleaching. Furthermore, it is not known whether these treatments can reverse possible changes in enamel microhardness without compromising the effectiveness of whitening treatment and interfering negatively in the final color of the teeth.

The objective of this in vitro study was to evaluate if previous surface treatments with fluoride, CPP-ACP, or $\mathrm{Nd}$ :YAG laser associated with fluoride have an influence on the microhardness of enamel, without interfering with the effectiveness of the bleaching procedure.

\section{Material and Methods}

2.1. Experimental Design. This study tested two main factors: surface treatments (control, fluoride, CPP-ACP, and Nd:YAG laser associated with fluoride) and time intervals (at baseline, after surface treatment, immediately after bleaching, and 7 days after bleaching). The experimental units consisted of 60 bovine incisors that were divided into 80 dental blocks, randomly divided as follows: 40 dental blocks for Knoop surface microhardness test ( $n=10$ /group) and 40 enamel blocks for analysis of color change ( $n=10$ /group).

2.2. Preparation of Bovine Dental Blocks. Sixty bovine teeth were observed under binocular stereoscopic microscope (Olympus, Hongo, Tokyo, Japan) at 25x magnification, and those showing cracks or wear on the buccal surface were discarded. Teeth were cleaned with periodontal curettes (Duflex, SS White, Rio de Janeiro, RJ, Brazil) to remove organic debris and were submitted to cleaning procedure with pumice and water (SS White) [28]. The crowns were separated from the roots using a diamond disc (15LC series, Buehler, Lake Bluff, IL, USA) coupled to a cutting machine (Labcut 1010, Extec, Enfield, CT, USA) under water-cooling.

2.3. Preparation of Dental Blocks for Microhardness Evaluation. Twenty bovine teeth were cut with a double-faced diamond disc (KG Sorensen, Barueri, SP, Brazil) under watercooling, to obtain 40 dental blocks $(5 \times 5 \mathrm{~mm}$, from the buccal surface of the teeth) and they were used for microhardness test. Blocks were embedded in acrylic resin (Jet-Classic, Cremer, Blumenau, SC, Brazil), leaving the buccal surface exposed. After the complete acrylic resin polymerization (approximately $1 \mathrm{~h}$ ), the blocks were planed and polished with silicon carbide sandpaper (Carbinet, Buehler, Lake Bluff, IL, USA) with decreasing grain (\#400, \#600, \#1200, and \#4000) for 30 seconds in each sandpaper $[13,29]$ to standardize the amount of enamel to be removed.

Finally, $1 \mu \mathrm{m}$ grain diamond paste (Buehler, Lake Bluff, IL, USA) applied with a felt disc (Texmet 1500, Buehler, Lake Bluff, IL, USA) was used for another $30 \mathrm{sec}$.

2.4. Preparation of Dental Blocks for Color Evaluation. Forty bovine crowns were cut with a double-faced diamond disc, under water-cooling to obtain 40 enamel blocks $(10 \times 10 \mathrm{~mm})$, $2 \mathrm{~mm}$ thick. Each block was planned with an individual abrasive silicon carbide paper (\#120 grit). Next, they were individually polished with silicon carbide sandpaper (Carbinet, Buehler, Lake Bluff, IL, USA) with decreasing grain (\#400, \#600, \#1200, and \#4000) for 30 seconds in each sandpaper $[13,29]$ to standardize the amount of enamel to be removed. Polishing was standardized using a metallic device that pressed the sample against the sandpaper.

After the end of the preparation, all samples were stored in distilled water until the beginning of the experiment.

2.5. Enamel Surface Treatment. The specimens of Group G1 were immersed in artificial saliva ( $\mathrm{pH}$ 6.8) for $24 \mathrm{~h}$ during the period in which the treatment of the other samples (experimental groups) was carried out. The artificial saliva used consisted of $\mathrm{CaCl}_{2} 2 \mathrm{H}_{2} \mathrm{O}(0.213 \mathrm{~g}), \mathrm{KH}_{2} \mathrm{PO}_{4}(0.738 \mathrm{~g})$, $\mathrm{KCl}$ (1.114 g), NaCl (0.381 g), TRIS buffer (12 g), and mucin (1.2 g) (corresponding values for each 11 of solution) [6].

Fluoride treatment (G2): a volume of $0.1 \mathrm{~mL}$ of $2 \%$ sodium fluoride (DFL, Rio de Janeiro, RJ, Brazil), measured in a disposable insulin syringe was applied on the buccal surface of the enamel for 1 minute. Afterwards, all the gel was carefully removed with gauze and the samples were stored in artificial saliva for 24 hours.

Treatment with CPP-ACP (G3): a volume of $0.1 \mathrm{~mL}$ of standard paste containing CPP-ACP (MI Paste, GC America, Chicago, IL, USA) was dispensed on the buccal surface enamel using an insulin syringe. The paste was applied on the surface for 3 minutes in a passive mode [30]. After this, all the paste was carefully removed with gauze and the samples were stored in artificial saliva for 24 hours.

Nd:YAG laser associated with fluoride (G4): fluoride gel was applied on the buccal surface of the enamel samples, as previously described in G2. Without removing the fluoride gel, samples were irradiated with laser $\mathrm{Nd}$ :YAG $(\lambda=1064 \mathrm{~nm})$ (Lares Research, Chico, CA, USA) using the following parameters: $50 \mathrm{~mJ}$ of energy, power of $0.50 \mathrm{~W}$ at $10 \mathrm{~Hz}$ repetition rate, $2.5 \mathrm{~J} / \mathrm{cm}^{2}$ energy density, and scanning the entire enamel surface for 30 seconds per sample [13, 15]. An optical fiber of $400 \mu \mathrm{m}$ in diameter was used, positioned perpendicularly to the enamel surface at approximately $1 \mathrm{~mm}$ (defocused mode). After irradiation, the samples were stored in artificial saliva for 24 hours.

2.6. Bleaching Technique. Twenty-four hours after completion of enamel surface treatments, samples of all groups were subjected to bleaching with $35 \%$ hydrogen peroxide 
(Whiteness HP, FGM, Joinville, SC, Brazil). The bleaching product contains the $35 \%$ hydrogen peroxide as active agent, thickener, red dye, and water glycol. The product was applied on the buccal surface of the enamel samples, in accordance with the manufacturer's instructions, consisting of three applications of a volume of approximately $0.1 \mathrm{~mL}$ for 15 minutes each, without the use of a light source to activate the whitening gel $[28,29]$. After bleaching procedures, the samples were thoroughly washed under running water and dried for analyses of surface microhardness and spectrophotometry.

2.7. Microhardness Test. Samples were submitted to Knoop surface microhardness tests with static load of $100 \mathrm{~g}$ for 15 seconds (Microhardness Tester HMV 200, Shimadzu, Kyoto, Japan). Five indentations were made on the sample surface at $100 \mu \mathrm{m}$ from each other, at predetermined time intervals: M1 (baseline, control), M2 (after surface treatment), M3 (immediately after bleaching), and M4 (7 days after bleaching). The mean value of the indentations at each time interval was considered for statistical analysis. The samples were stored in artificial saliva between the different times of measurement.

2.8. Color Change Evaluation. The system used to measure color in the current study was developed by the CIE (Commission Internationale de L'Eclairage, 1976) [31]. Color was evaluated at four different time intervals: baseline (M1, control), after surface treatments (M2), immediately after bleaching (M3), and 7 days after bleaching (M4).

Between readouts, the samples were kept in artificial saliva to prevent dehydration and the color difference was calculated using the values of $L^{*} a^{*} b^{*}$ obtained after the initial readout (M1) and after each further readout (M2, M3, and M4). The color coordinates in three-dimensional system are $L^{*}=$ luminosity coordinate, which is achromatic and ranges from 0 (black) to 100 (white) and the $a^{*}=$ chromatic coordinate green-red $\left(-a^{*}=\right.$ green, $\left.+a^{*}=\operatorname{red}\right)$ and $b^{*}=$ blue-yellow color coordinate $\left(-b^{*}=\right.$ blue, $+b^{*}=$ yellow). The total change in color (or the change in color perception) of each sample at different time intervals $(\Delta E)$ was calculated using the formula: $\Delta E=\left[(\Delta L)^{2}+(\Delta a)^{2}+(\Delta b)^{2}\right]^{0.5}$ for the different readout times [32].

The UV-Visible spectrometer (Cintra 10, Hitachi Model U-3501, Tokyo, Japan) requires standardized $10 \times 10 \mathrm{~mm}$ samples to automatically read the specimens to guarantee that the readings will be performed in the same location.

In the intervals between readings, the samples were kept in artificial saliva to avoid dehydration. They were dried with absorbent paper just before the reading procedure.

2.9. Statistical Analysis. For both microhardness and color change evaluation, data were submitted to statistical analysis using ANOVA two-way (treatment and time intervals) followed by Tukey's test to examine statistically significant differences between groups. Minitab 17 Statistical Software was used for the statistical analysis with significance level of $5 \%$.
TABLE 1: Mean surface Knoop microhardness (KHN) values and standard error for the factor time intervals.

\begin{tabular}{lc}
\hline Groups & Microhardness \\
\hline Baseline, control (M1) & $273.50 \pm 6.65 \mathrm{~A}$ \\
After treatment (M2) & $273.12 \pm 6.65 \mathrm{~A}$ \\
Immediately after bleaching (M3) & $255.77 \pm 6.65 \mathrm{~B}$ \\
7 days after bleaching (M4) & $266.07 \pm 6.65 \mathrm{AB}$ \\
\hline
\end{tabular}

Different letters indicate statistically significant difference.

TABLe 2: Mean surface Knoop microhardness (KHN) values and standard error for the factor treatment.

\begin{tabular}{lc}
\hline Groups & Microhardness \\
\hline Control (G1) & $276.47 \pm 6.65 \mathrm{~A}$ \\
Fluoride (G2) & $266.45 \pm 6.65 \mathrm{~A}$ \\
CPP-ACP (G3) & $265.67 \pm 6.65 \mathrm{~A}$ \\
Fluoride + Nd:YAG laser (G4) & $259.87 \pm 6.65 \mathrm{~A}$ \\
\hline
\end{tabular}

Different letters indicate statistically significant difference.

\section{Results}

3.1. Microhardness Evaluation. ANOVA indicated statistically significant result for the factor time intervals $(p=$ 0.02 ), indicating that, immediately after bleaching, all groups presented lower microhardness. After 7 days in saliva, samples presented an intermediate microhardness performance (Table 1). On the other hand, the main factor treatments ( $p=$ $0.09)$ and the interaction between factors $(p=0.99)$ were not statistically different (Table 2 ). This result indicates that previous treatments were not able to prevent the reduction in microhardness caused by bleaching, but, after 7 days of saliva storage, the microhardness was recovered.

3.2. Color Evaluation. For the evaluation of color change, this study has two dependent variables:

(i) Change of luminosity, $\Delta L$, ranging from 0 to 100 , featuring the chromatic spindle drives black (0) and white (100)

(ii) $\Delta E$, total color difference, within the CIE $L^{*} a^{*} b^{*}$, 1976, comprising the total variations of $\Delta L \Delta b \Delta a$

Change of luminosity values is shown in Table 3, while the total color change is in Table 4.

There was no statistically significant difference in luminosity change regardless of the type of treatment performed in all time intervals. Considering the factor time intervals in each treatment, in G1, G2, and G4, the luminosity increased after bleaching and was maintained after 7 days of storage, but G3 showed a different performance. When, in CPP-ACP $(\triangle L P)$, a significant decrease in the luminosity was observed, but it did not impair bleaching $(\Delta L I)$ and its recovery after 7 days of storage (Table 3 ).

$\Delta E_{P}$ corresponded to total variation of color after treatments, $\Delta E_{i}$ immediately after the bleaching, and $\Delta E_{7}$ seven days after the end of the bleaching. Table 4 indicates that no statistically significant difference was observed for treatments in each time interval. Also, despite the treatment being 
TABLE 3: Means and standard deviations for the $\Delta L$ values.

\begin{tabular}{lccc}
\hline Groups & $\Delta L_{P}$ & $\Delta L_{I}$ & \multicolumn{1}{c}{$\Delta L_{7}$} \\
\hline Control (G1) & $0.03 \pm 0.46^{\mathrm{Ab}}$ & $2.00 \pm 1.55^{\mathrm{Aa}}$ & $1.68 \pm 1.32^{\mathrm{Aa}}$ \\
Fluoride (G2) & $0.46 \pm 1.05^{\mathrm{Ab}}$ & $2.74 \pm 1.03^{\mathrm{Aa}}$ & $2.11 \pm 1.06^{\mathrm{Aa}}$ \\
CPP-ACP (G3) & $-0.26 \pm 0.99^{\mathrm{Ac}}$ & $2.71 \pm 1.64^{\mathrm{Aa}}$ & $1.83 \pm 1.33^{\mathrm{Ab}}$ \\
Nd:YAG laser + Fluoride (G4) & $-0.08 \pm 1.23^{\mathrm{Ab}}$ & $1.51 \pm 0.35^{\mathrm{Aa}}$ & $0.91 \pm 0.58^{\mathrm{Aa}}$ \\
\hline
\end{tabular}

Different uppercase letters indicate statistically significant differences within columns.

Different lowercase letters indicate statistically significant differences within rows.

$\Delta L_{P}$ : change of luminosity after treatment of enamel; $\Delta L_{I}$ : change of luminosity immediately after bleaching; $\Delta L_{7}$ : change of luminosity 7 days after bleaching.

TABle 4: Means and standard deviations for the $\Delta E$ values.

\begin{tabular}{lccr}
\hline Groups & $\Delta E_{P}$ & $\Delta E_{I}$ & $\Delta E_{7}$ \\
\hline Control & $0.37 \pm 0.40^{\mathrm{Ab}}$ & $3.17 \pm 2.10^{\mathrm{Aa}}$ & $3.26 \pm 1.83^{\mathrm{Aa}}$ \\
Fluoride & $0.95 \pm 0.59^{\mathrm{Ab}}$ & $3.43 \pm 1.00^{\mathrm{Aa}}$ & $3.05 \pm 1.22^{\mathrm{Aa}}$ \\
CPP-ACP & $0.94 \pm 0.62^{\mathrm{Ab}}$ & $3.09 \pm 1.57^{\mathrm{Aa}}$ & $3.10 \pm 0.88^{\mathrm{Aa}}$ \\
Nd:YAG laser + fluoride & $1.13 \pm 0.65^{\mathrm{Ab}}$ & $2.72 \pm 1.51^{\mathrm{Aa}}$ & $2.79 \pm 1.17^{\mathrm{Aa}}$ \\
\hline
\end{tabular}

Different uppercase letters indicate statistically significant differences within columns.

Different lowercase letters indicate statistically significant differences within rows.

Error between groups $=0,55$.

Error intragroups: $=0,42$.

$n=10$, alfa 0,05 .

performed or not, the bleaching procedure was effective in increasing the color change that remained changed after 7 days.

\section{Discussion}

Many studies have reported a decrease in microhardness $[7,8,32]$, in addition to increased enamel porosity [33], permeability [6], and roughness [3,11] after bleaching procedures. Therefore, the aim of this study was to find resources to minimize or even prevent these changes, such as the use of fluoride, CPP-ACP, and Nd:YAG laser associated with fluoride, when applied $24 \mathrm{~h}$ before bleaching.

Samples from the control group were the ones to show a reduction on microhardness at the time immediately after bleaching. These findings agree with the literature $[9,32]$. Also, considering the treatments solely, it was verified that, in all experimental groups, the enamel microhardness was recovered after 7 days. This can be justified by the ability of fluoride, calcium, and phosphate ions to form a compound that is more resistant to acid attacks, since there is synergism between these ions with an artificial saliva [20-22].

Using laser in combination with fluoride increases the resistance of enamel to acids, thereby promoting a preventive effect $[15,16]$, because the heat promotes the dissolution of the enamel prisms and their recrystallization, thus decreasing permeability. The presence of fluoride during irradiation promotes the remineralization of enamel $[14,16]$.

Regarding the CPP-ACP treated samples, it is suggested that this treatment could have led to chemical changes in the tooth substrate. This could have had a negative influence on enamel brightness, because the results of this group showed decrease in brightness, while microhardness immediately after bleaching was similar to that observed after 7 days. Nevertheless, chemical tests would be required to confirm the hypothesis that $\mathrm{CPP}-\mathrm{ACP}$-induced chemical alterations in the enamel. Also, the follow-up time considered in the present study (7 days) may not be enough to make conclusions on the real effect of CPP-ACP on enamel brightness. Longterm evaluation would be necessary to evaluate it, since the subproducts of the CPP-ACP on the enamel surface could be no more existent after a higher exposure time to saliva.

It is believed that as time passes the cumulative effects of CPP-ACP with the saliva promotes adequate protection before the whitening, but 7 days before was the time we considered ideal for performing preventive measures before the dental bleaching.

Irradiation with Nd:YAG laser promotes the formation of wider enamel prisms and reduces enamel permeability [13, 14], so it is questionable whether whitening would be possible under these conditions, since the free radicals formed during the bleaching process must penetrate the tooth structure to react with the pigments. However, the results of this research did not reveal significant color alterations $(\Delta E)$ in the irradiated samples maybe because the bleaching agent may have been prevented from penetrating the enamel properly.

Regarding total color difference $(\Delta E)$, the analysis between groups showed no significant differences at different readout times. However, there was a significant color difference between all groups immediately after bleaching, which remained after 7 days. Johnston (2009) [34] reported that when $\Delta E$ is greater than or equal to 1 , the human eye detects color differences. In this study, the $\Delta E$ values of all groups were not statistically different after 7 days and the color remained constant in all groups. Thus, it is possible to suggest that enamel treatments did not negatively affect the effectiveness of whitening.

Finally, further studies should be conducted, considering longer periods of use of products for surface treatment or even different products. Although it was shown that the side 
effects were minimized by some of the surface treatments and that they did not have any influence on the whitening potential of bleaching agents, performing these treatments 24 hours prior to enamel exposure to $35 \%$ hydrogen peroxide was insufficient to prevent the mineral changes caused by bleaching.

\section{Conclusions}

None of the treatments tested could influence enamel microhardness. But it is important to highlight that bleaching decreases microhardness, but not in a permanent way. After 7 days of saliva storage, this reduction is recovered. Also, the treatments performed did not impair bleaching effectiveness. Based on our results, we can conclude that there is no reason to perform previous treatments before bleaching to prevent the decrease in microhardness. But, if these treatments are necessary for some other reason, the substances can be applied without compromising the esthetic result of the bleaching procedure.

\section{Competing Interests}

There are no competing interests.

\section{Acknowledgments}

The authors would like to thank the State of São Paulo Research Foundation, FAPESP (Grant no. 07/54666-9) and CNPq (Grant no. 304198/2010-2) for the financial support provided. They also thank CAPES for the Doctoral scholarship awarded to the first author. The authors also express their gratitude to FGM and GC America by donating products to research. The authors would like to thank also the Fundação de Amparo à Pesquisa e Desenvolvimento Científico do Maranhão, FAPEMA (Portuguese acronym for the Maranhão State Research Foundation) for supporting the publication of this article.

\section{References}

[1] J. F. Bortolatto, H. Pretel, C. S. Neto, M. F. Andrade, G. Moncada, and O. B. Oliveira Jr., "Effects of LED-laser hybrid light on bleaching effectiveness and tooth sensitivity: A Randomized Clinical Study," Laser Physics Letters, vol. 10, no. 8, Article ID 085601, 2013.

[2] S. B. Berger, V. Cavalli, G. M. B. Ambrosano, and M. Giannini, "Changes in surface morphology and mineralization level of human enamel following in-office bleaching with $35 \%$ hydrogen peroxide and light irradiation," General Dentistry, vol. 58, no. 2, pp. e74-e79, 2010.

[3] D. G. Soares, A. P. D. Ribeiro, N. T. Sacono, A. D. Loguércio, J. Hebling, and C. A. D. S. Costa, "Mineral loss and morphological changes in dental enamel induced by a $16 \%$ carbamide peroxide bleaching gel," Brazilian Dental Journal, vol. 24, no. 5, pp. 517521, 2013.

[4] R. De Oliveira, A. F. Paes Leme, and M. Giannini, "Effect of a carbamide peroxide bleaching gel containing calcium or fluoride on human enamel surface microhardness," Brazilian Dental Journal, vol. 16, no. 2, pp. 103-106, 2005.
[5] P. Soldani, C. M. Amaral, and J. A. Rodrigues, "Microhardness evaluation of in situ vital bleaching and thickening agents on human dental enamel," The International journal of periodontics \& restorative dentistry, vol. 30, no. 2, pp. 203-211, 2010.

[6] S. da Silva Ferreira, J. L. N. Araújo, O. N. Morhy, C. M. C. Tapety, M. N. Youssef, and M. A. P. Sobral, "The effect of fluoride therapies on the morphology of bleached human dental enamel," Microscopy Research and Technique, vol. 74, no. 6, pp. 512-516, 2011.

[7] I. Lewinstein, N. Fuhrer, N. Churaru, and H. Cardash, "Effect of different peroxide bleaching regimens and subsequent fluoridation on the hardness of human enamel and dentin," Journal of Prosthetic Dentistry, vol. 92, no. 4, pp. 337-342, 2004.

[8] A. Wiegand, M. Schreier, and T. Attin, "Effect of different fluoridation regimes on the microhardness of bleached enamel," Operative Dentistry, vol. 32, no. 6, pp. 610-615, 2007.

[9] M. B. Rezvani, M. Karimi, R. Akhavan Rasoolzade, and R. Haghgoo, "Comparing the effects of whey extract and casein phosphopeptide-amorphous calcium phosphate (CPP-ACP) on enamel microhardness," Journal of Dentistry, vol. 16, pp. 49-53, 2015.

[10] M. Oshiro, K. Yamaguchi, T. Takamizawa et al., "Effect of CPPACP paste on tooth mineralization: an FE-SEM study," Journal of oral science, vol. 49, no. 2, pp. 115-120, 2007.

[11] F. G. de Carvalho, V. L. M. Brasil, T. J. D. S. Filho, H. L. Carlo, R. L. D. Santos, and B. A. S. G. de Lima, "Protective effect of calcium nanophosphate and CPP-ACP agents on enamel erosion," Brazilian Oral Research, vol. 27, no. 6, pp. 463-470, 2013.

[12] L. Zheng, J. Zheng, Y. F. Zhang, L. M. Qian, and Z. R. Zhou, "Effect of CPP-ACP on the remineralization of acid-eroded human tooth enamel: nanomechanical properties and microtribological behaviour study," Journal of Physics D: Applied Physics, vol. 46, no. 40, Article ID 404006, 2013.

[13] H. G. D. Boari, P. A. Ana, C. P. Eduardo, G. L. Powell, and D. M. Zezell, "Absorption and thermal study of dental enamel when irradiated with Nd:YAG laser with the aim of caries prevention," Laser Physics, vol. 19, no. 7, pp. 1463-1469, 2009.

[14] D. Rios, A. C. Magalhães, M. A. D. A. M. Machado et al., "In vitro evaluation of enamel erosion after Nd:YAG laser irradiation and fluoride application," Photomedicine and Laser Surgery, vol. 27, no. 5, pp. 743-747, 2009.

[15] D. M. Zezell, H. G. D. Boari, P. A. Ana, C. D. P. Eduardo, and G. L. Powell, "Nd:YAG laser in caries prevention: a clinical trial," Lasers in Surgery and Medicine, vol. 41, no. 1, pp. 31-35, 2009.

[16] P. A. Ana, C. M. F. Kauffmann, L. Bachmann et al., "FT-Raman spectroscopic analysis of Nd:YAG and Er,Cr:YSGG laser irradiated enamel for preventive purposes," Laser Physics, vol. 24, no. 3, Article ID 035603, 2014.

[17] A. B. Borges, K. C. K. Yui, T. C. D’Avila, C. L. Takahashi, C. R. G. Torres, and A. L. S. Borges, "Influence of remineralizing gels on bleached enamel microhardness in different time intervals," Operative Dentistry, vol. 35, no. 2, pp. 180-186, 2010.

[18] J. J. Jardim, M. A. Pagot, and M. Maltz, "Artificial enamel dental caries treated with different topical fluoride regimes: An In Situ Study," Journal of Dentistry, vol. 36, no. 6, pp. 396-401, 2008.

[19] C. Llena, L. Forner, and P. Baca, "Anticariogenicity of casein phosphopeptide-amorphous calcium phosphate: a review of the literature," Journal of Contemporary Dental Practice, vol. 10, no. 3, pp. 1-9, 2009.

[20] E. C. Reynolds, "Casein phosphopeptide-amorphous calcium phosphate: the scientific evidence," Advances in Dental Research, vol. 21, no. 1, pp. 25-29, 2009. 
[21] M. A. Robertson, C. H. Kau, J. D. English, R. P. Lee, J. Powers, and J. T. Nguyen, "MI Paste Plus to prevent demineralization in orthodontic patients: a prospective randomized controlled trial," American Journal of Orthodontics and Dentofacial Orthopedics, vol. 140, no. 5, pp. 660-668, 2011.

[22] F. J. Wegehaupt, T. T. Tauböck, A. Stillhard, P. R. Schmidlin, and T. Attin, "Influence of extra- and intra-oral application of CPP-ACP and fluoride on re-hardening of eroded enamel," Acta Odontologica Scandinavica, vol. 70, no. 3, pp. 177-183, 2012.

[23] C. Poggio, M. Lombardini, A. Dagna, M. Chiesa, and S. Bianchi, "Protective effect on enamel demineralization of a CPP-ACP paste: an AFM in vitro study," Journal of Dentistry, vol. 37, no. 12, pp. 949-954, 2009.

[24] A. B. Giulio, Z. Matteo, I. P. Serena, M. Silvia, and C. Luigi, "In vitro evaluation of casein phosphopeptide-amorphous calcium phosphate (CPP-ACP) effect on stripped enamel surfaces. A SEM investigation," Journal of Dentistry, vol. 37, no. 3, pp. 228232, 2009.

[25] R. F. Sognnaes and R. H. Stern, "Laser effect on resistance of human dental enamel to demineralization," Journal of Southern California Dental Association, vol. 33, pp. 328-329, 1965.

[26] T. Oho and T. Morioka, "A possible mechanism of acquired acid resistance of human dental enamel by laser irradiation," Caries Research, vol. 24, no. 2, pp. 86-92, 1990.

[27] J. E. P. Pelino, J. B. Mello, C. P. Eduardo, and A. O. C. Jorge, "In vitro study of the Nd:YAG laser effect on human dental enamel: optical and scanning electron microscope analysis," Journal of Clinical Laser Medicine and Surgery, vol. 17, no. 4, pp. 171-177, 1999.

[28] A. D. N. Lago, P. M. De Freitas, and N. G. Netto, "Evaluation of the bond strength between a composite resin and enamel submitted to bleaching treatment and etched with Er:YAG laser," Photomedicine and Laser Surgery, vol. 29, no. 2, pp. 9195, 2011.

[29] A. D. N. Lago and N. Garone-Netto, "Microtensile bond strength of enamel after bleaching," Indian Journal of Dental Research, vol. 24, no. 1, pp. 104-109, 2013.

[30] N. Srinivasan, M. Kavitha, and S. C. Loganathan, "Comparison of the remineralization potential of CPP-ACP and CPP-ACP with 900 ppm fluoride on eroded human enamel: an in situ study," Archives of Oral Biology, vol. 55, no. 7, pp. 541-544, 2010.

[31] Commision Internationale de I'Eclairage, Colorimetry CIE Publication, supplement 2, no. 15, Commision Internationale de I’Eclairage, Vienna, Austria, 1976.

[32] T. Attin, P. R. Schmidlin, F. Wegehaupt, and A. Wiegand, "Influence of study design on the impact of bleaching agents on dental enamel microhardness: a review," Dental Materials, vol. 25, no. 2, pp. 143-157, 2009.

[33] Y. H. Kwon, M. S. Huo, K. H. Kim, S. K. Kim, and Y. J. Kim, "Effects of hydrogen peroxide on the light reflectance and morphology of bovine enamel," Journal of Oral Rehabilitation, vol. 29, no. 5, pp. 473-477, 2002.

[34] W. M. Johnston, "Color measurement in dentistry," Journal of Dentistry, vol. 37, no. 1, pp. e2-e6, 2009. 


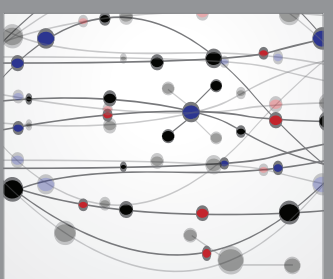

The Scientific World Journal
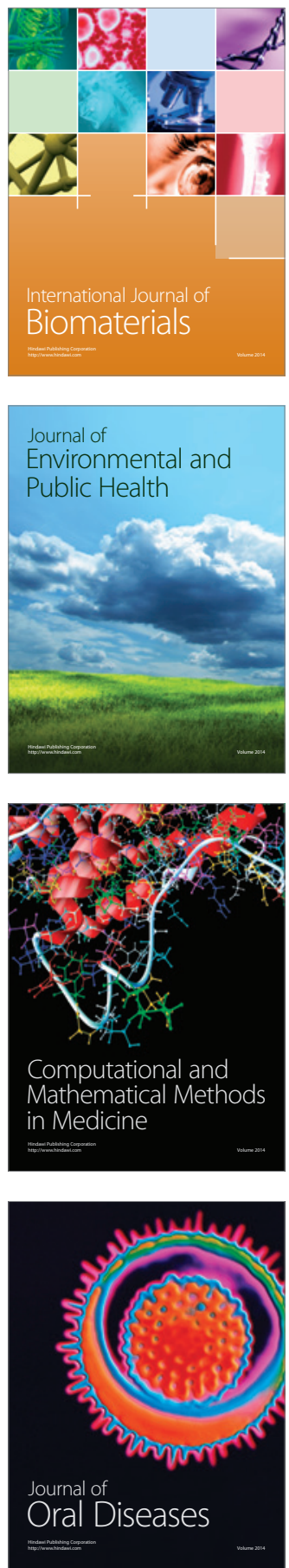
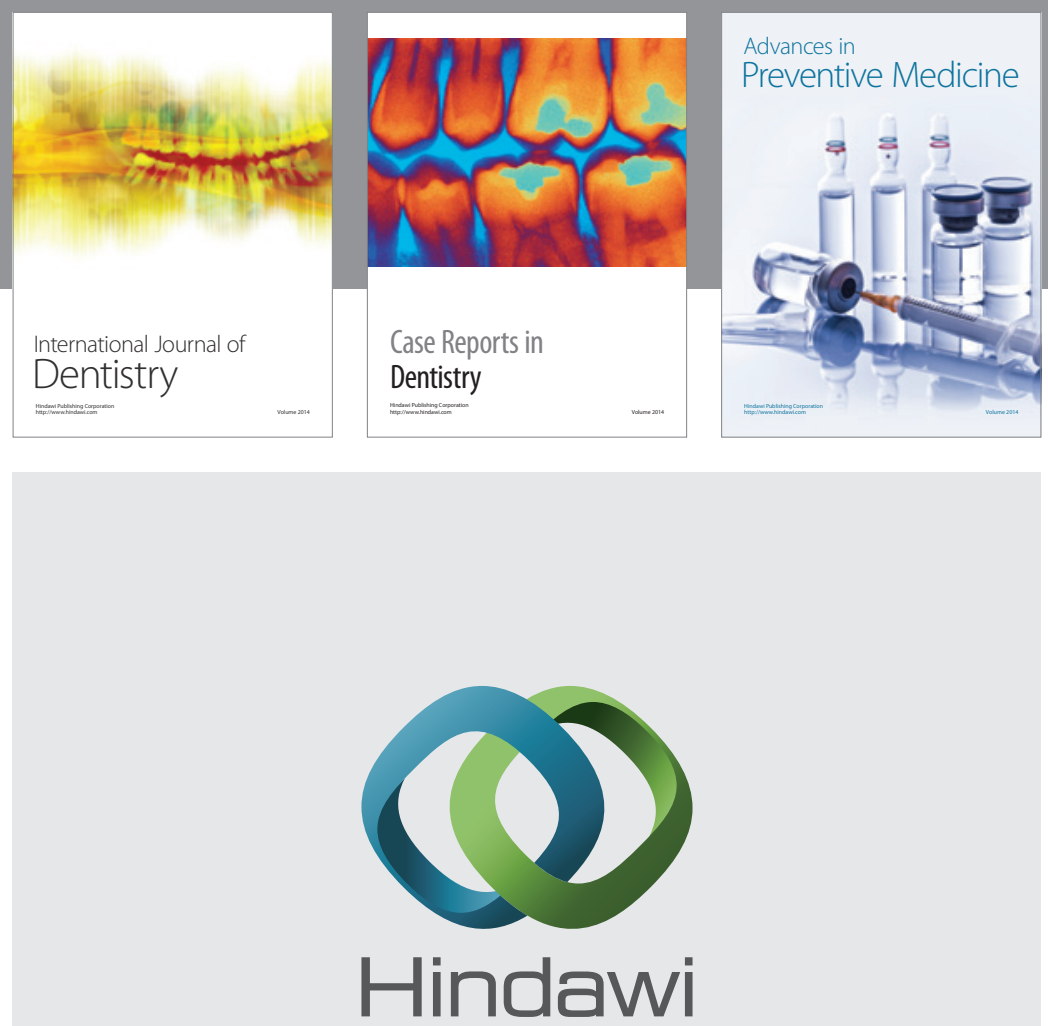

Submit your manuscripts at

https://www.hindawi.com
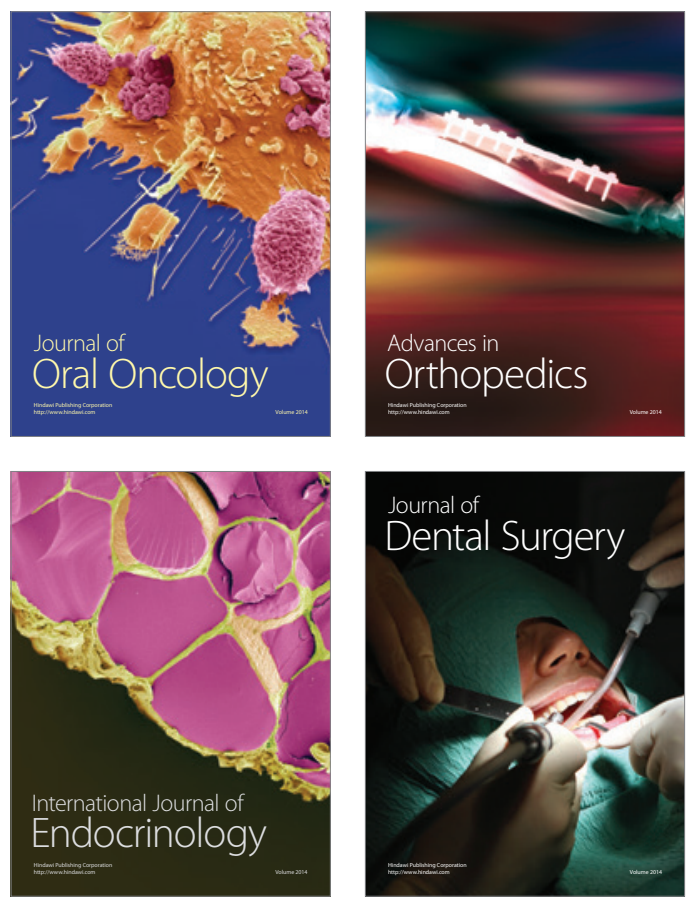
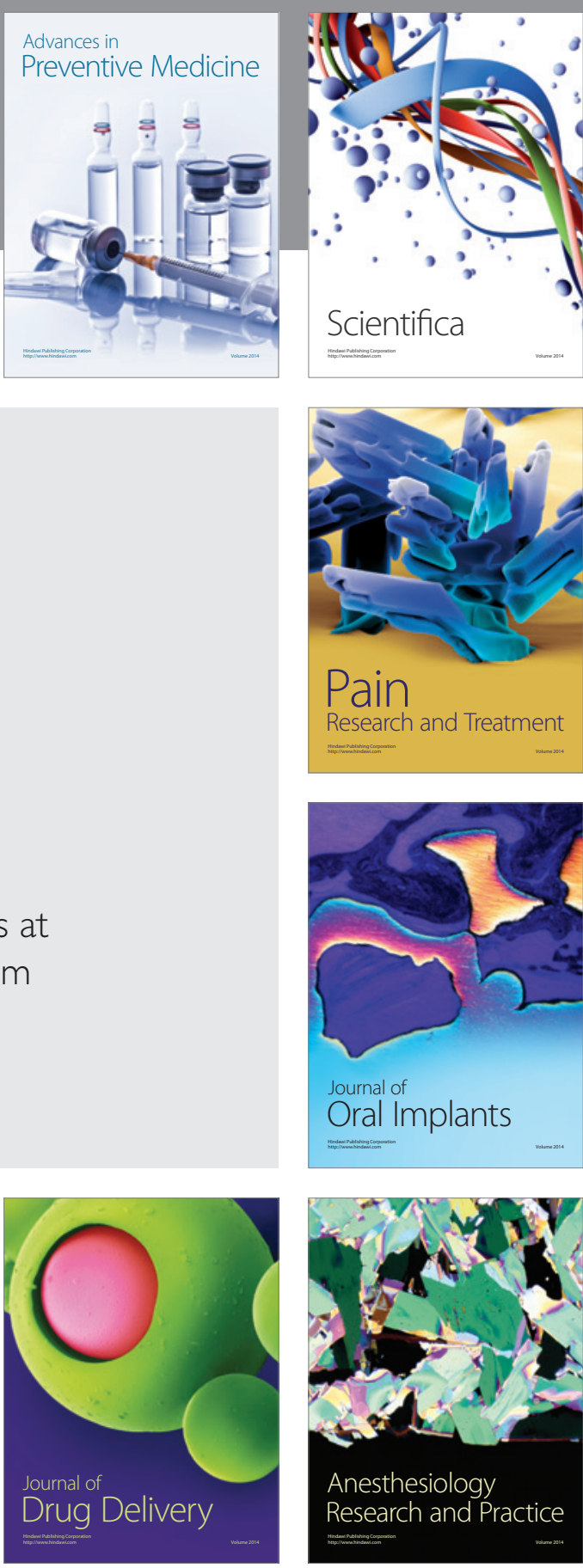

Scientifica
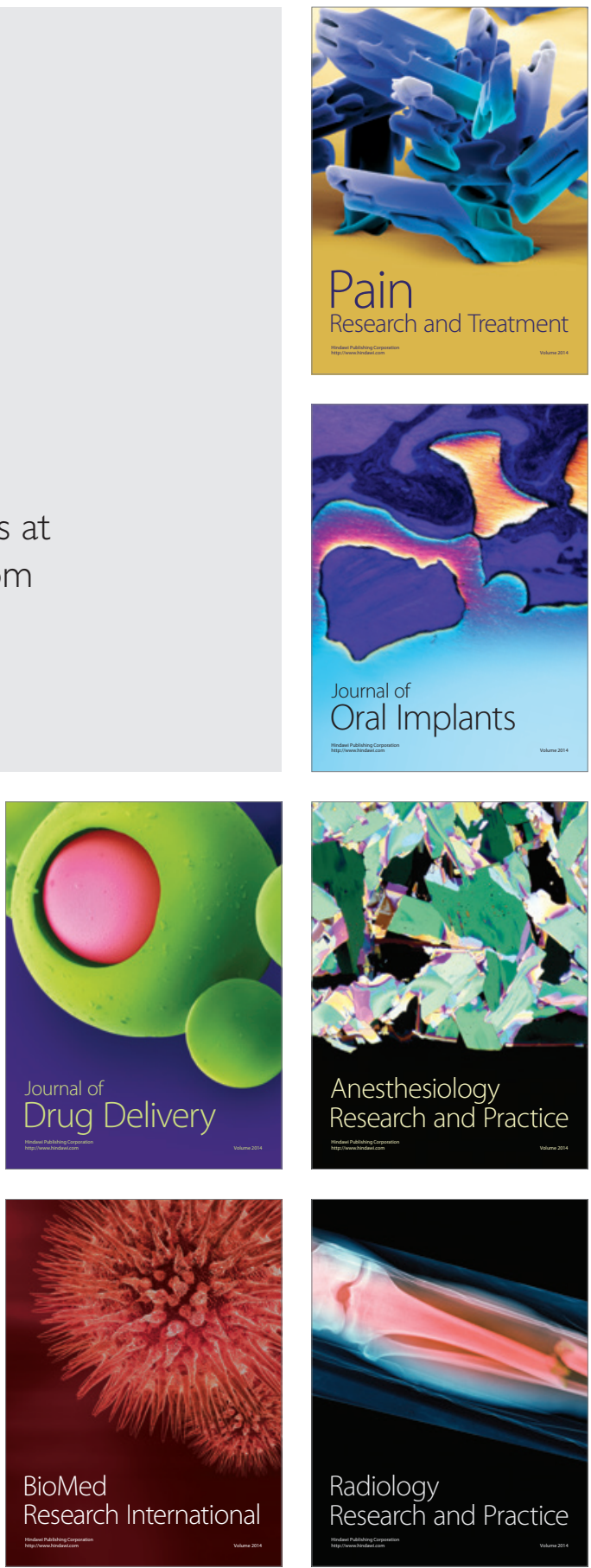